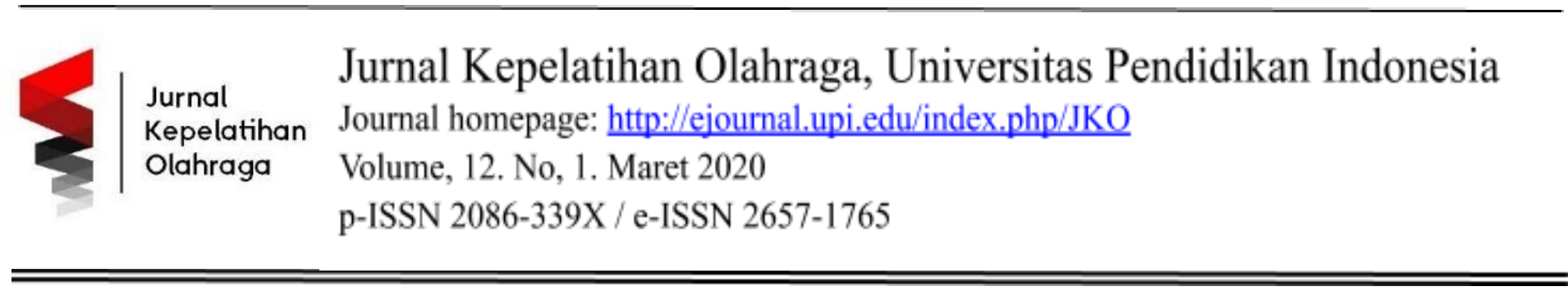

\title{
Peningkatan Keterampilan Atlet Bola Voli melalui Latihan Life Kinetik
}

\author{
Dika Nur Iqbal *, Muhamad Tafaqurl \\ ${ }^{1}$ Pendidikan Kepelatihan Olahraga, Fakultas Pendidikan Olahraga dan Kesehatan, Universitas \\ Pendidikan Indonesia, Bandung, Indonesia \\ *Correspondence: E-mail: dikojerikoo20@gmail.com
}

\begin{abstract}
A B S T R A C T S
The purpose of this study was to study the effect of Life Kinetik exercises on improving the skills of volleyball athletes. This exercise combines psychomotor aspects (physical activity) and cognitive aspects at the same time so as to improve cognitive abilities. The method used in this study is an experimental method with a Pretest-Posttest Control Group Design research design. The population of this study were all female athletes who were active in Indonesian Volleyball UKM. The sample of this study amounted to 6 experimental group athletes and 6 control group athletes. Analysis of the study used the Kolmogorov-Smirnov and Shapiro-Wilk normality test, and paired t-test and independent t-test hypotheses. The results of the study showed that Life Kinetik training had a significant effect on increasing the skills of female volleyball. Therefore, researchers recommend volleyball coaches to incorporate Life Kinetik training into an exercise program as a warm up to enter technical training.
\end{abstract}

(C) 2019 Tim Pengembang Jurnal Kepelatihan Olahraga

A B S T R A K

Tujuan Penelitian ini untuk mengetahui pengaruh latihan Life Kinetik terhadap peningkatan keterampilan atlet bola voli. latihan ini memadukan antara aspek psikomotor (kegiatan fisik) dan aspek kognitif dalam satu waktu yang sama sehingga dapat meningkatkan kemampuan kognitif. Metode penelitian menggunakan metode eksperimen dengan desain penelitian pretest-posttest control group design. Populasi dari penelitian ini adalah seluruh mahasiswa atlet putri yang aktif dalam UKM Bola Voli Universitas Pendidikan Indonesia. Sampel dari penelitian ini berjumlah 6 atlet kelompok eksperimen dan 6 atlet kelompok kontrol. Analisis penelitian menggunakan uji normalitas Shapiro-Wilk, dan uji hipotesis paired t-test dan independent t-test, Hasil dari penelitian menunjukkan bahwa latihan Life Kinetik memberikan pengaruh yang signifikan terhadap peningkatan keterampilan atlet putri Bola Voli. Maka dari itu, peneliti merekomendasikan pelatih bola voli untuk memasukkan latihan Life Kinetik ke dalam program latihan sebagai pemanasan untuk masuk ke latihan teknik.

\author{
A R T I C L E I N F O \\ Article History: \\ Received 22 Nov 2019 \\ Revised 8 Jan 2020 \\ Accepted 30 Jan 2020 \\ Available online 30 March 2020
}

Keyword:

Life Kinetik, Skills, and

Volleyball Athletes. 


\section{PENDAHULUAN}

Pelatihan Life Kinetik merupakan model latihan mental yang tergolong baru di Indonesia, awalnya latihan Life Kinetik ini berkembang di Jerman dengan istilah life-kinetik yang digunakan untuk melatih mental seseorang termasuk pada atlet profesional. (Saputra, dkk. 2017) "Life Kinetik training influences the coordination especially for the skilled athlete". Sedangkan penelitian lainnya bahwa, "latihan Life Kinetik memberikan pengaruh yang signifikan terhadap hasil keterampilan olahraga permainan", (Jatikusuma, 2017). Disamping itu pemecahan latihan tersebut memberikan solusi untuk melatih otak manusia agar memiliki keputusan yang tepat.

Permasalahan bola voli sering terjadi melakukan keputusan antisipasi bola pertama dan melakukan penyerangan yang kurang tepat, kendala yang terjadi adalah gerakan yang dilakukan hanya membuang tenaga yang tidak efektif dan efisien dikarenakan kesalahan yang dilakukannya sendiri. Keputusan dan teknik dasar pemain bola voli harus didasarkan kondisi fisik yang prima dan teknik dasar yang tinggi. Pentingya "teknik dasar dan kondisi fisik pun diungkapkan oleh Purwanto (2012).

Model pelatihan ini memberikan inspirasi baru untuk diterapkan di indonesia pada setiap individu dalam melatih mental khususnya masalah kognisinya. Pelatihan ini merupakan teknik pelatihan inovatif dan khusus dirancang untuk meningkatkan daya "kognisi (cognitive), multi-tugas (multitasking), dan konsentrasi agar seseorang dapat mengembangkan sumber daya (otak) dan segala potensi yang dimilikinya dengan maksimal", Komarudin (2018).

Tujuan Latihan ini memberikan stimulus sistem kinerja otak untuk meningkatkan daya konsentrasi, motivasi, kecerdasan, multitasking (tugas ganda), daya ingat dan atensi, resistensi terhadap stress, dan fitness (Kuswari, 2014). diperkuat juga oleh penelitian yang dilakukan Komarudin (2018) bahwa "latihan ini memiliki banyak pengaruh, salah satunya adalah terhadap motivasi baik di dalam olahraga beregu maupun olahraga perorangan'. Penelitian lainpun menyebutkan 'adanya hubungan motivasi dengan keterampilan dasar, Motivasi memberikan dampak kuat terhadap keterampilan gerak' (Putra, 2013). Artinya dampak latihan dari Life Kinetik ini memberikan banyak komponen lain untuk dapat berkembang.

Demikian pula pada cabang olahraga bola voli, kompleksitas gerak yang harus dimiliki seorang atlet bola voli mengharuskan mereka untuk berlatih intensif dan panjang serta model latihan yang inovatif. Pelatihan Life Kinetik dipandang sebagai model latihan yang cocok untuk meningkatkan kemampuan atlet bola voli di cabang olahraga bola voli, baik dari sisi kemampuan fisik, kognitif, dan mental., Mengingat koordinasi gerak pada cabang olahraga bola voli sangat komplek serta membutuhkan komponen fisik lainnya, seperti koordinasi, kelincahan, dan keseimbangan dengan tugas secara kognitif yang dapat mengembangkan konsentrasi, fokus dan mental 
(berpikir kritis), yang kesemuanya itu sangat dibutuhkan pada cabang olahraga bola voli. dan tujuan penelitian ini untuk mengungkap pengaruh latihan Life Kinetik terhadap peningkatan keterampilan atlet bola voli

\section{METODE}

Penelitian ini menggunakan metode eksperimen dengan desain the One-Group Pretest-Posttest Design. Alur penelitian yang dilakukan dengan cara mengidentifikasi masalah, meninjau teori-teori, pemilihan partisipan, pengambilan data, analisis penafsiran data, pelaporan dan evaluasi penelitian.

Teknik pengumpulan data pada penelitian ini dilakukan dengan menggunakan alat tes. Adapun alat tes yang digunakan sebagai Instrumen penelitian menggunakan tes keterampilan bola voli (Richard, 1980) berupa servis, passing bawah, dan passing atas. dengan kelengkapan terdiri dari bola voli, lapangan, dinding yang sudah ditandai, stopwatch beserta net dan alat tulis. Servis untuk petunjuk penilain berdiri di belakang garis lapangan, sampel memiliki kesempatan melakukan servis sebanyak 10 kali dan lapangan telah diberi tanda atau setiap tanda memiliki nilainya masing-masing. Berikutya untuk Passing atas dan bawah petunjuk penilaian dengan cara berdiri di belakang garis yang sudah ditentukan, bola dipegang terlebih dahulu. Waktu 1 menit untuk melakukan passing bawah atau atas sebanyak mungkin dihitung setelah sentuhan pertama. Sebelum melakukan tes sesungguhnya diberi waktu untuk melakukan uji coba tes selama 20 detik. Pada saat tes yang sesungguhnya diberikan 3 kali kesempatan melakukan tes. Hasil 3 kali kesempatan tes akan diambil 2 skor tertinggi kemudian diambil rata rata skor.

\subsection{Subjek Penelitian}

Populasi dalam penelitian ini adalah atlet UKM Bola Voli dengan jumlah atlet 46 orang. Dalam pemilihan populasi ini berniat untuk mencoba meningkatkan keterampilan bermain voli. Penentuan sampel ini melalui pendekatan teknik purposive sampling dengan kategori pemain inti atlet putri cabang olahraga bola voli yang berjumlah 12 atlet dan peneliti membagi dua kelompok enam orang sebagai kelompok eksperimen dan enam orang kelompok kontrol.

\subsection{Prosedur Penelitian}

Tahapan penelitian yang dilakukan adalah sebagai berikutnya: (1) Membuat program latihan (2) Menentukan populasi dan sampel (3) Melakukan tes awal (4) Memberikan treatment pada kelompok A dan kelompok B (5) Melakukan tes akhir (6) Melakukan analisis data (7) Setelah data diolah selanjutnya melakukan penafsiran hasil analisis data hingga dapat menjadi acuan dalam pengambilan kesimpulan.

\section{HASIL PENELITIAN}

Hasil perhitungan dan Uji signifikansi dapat dilihat pada Tabel 3.1.

Tabel 3.1. Uji Peningkatan Keterampilan Voli

\begin{tabular}{lccc}
\hline \multicolumn{1}{c}{ Variabel } & Sig. (2-tailed) & A & Keterangan \\
\hline Passing Bawah & 0.000 & 0,05 & Signifikan \\
\hline Passing Atas & 0.001 & 0,05 & Signifikan \\
\hline Servis & 0.001 & 0,05 & Signifikan \\
\hline
\end{tabular}


Berdasarkan tabel 3.1. menunjukan bahwa Nilai Sig atau Probabilitas dari setiap variabel baik kelompok $<0,05$, maka dapat disimpulkan bahwa terdapat peningkatan yang signifikan terhadap keterampilan voli UKM Voli UPI.

\section{PEMBAHASAN}

Upaya penggunaan latihan Life Kinetik untuk meningkatkan kemampuan keterampilan dalam penelitian ini menemukan hasil yang positif. Berdasarkan penelitian dan pengolahan data yang dilakukan membuktikan bahwa terdapat pengaruh pelatihan Life Kinetik terhadap keterampilan atlet bola voli UKM Bola Voli Universitas Pendidikan Indonesia.

Aktivitas fisik dapat merangsang otak, dalam Khan dan Hillman (2014, hlm. 138) mengungkapkan bahwa aktivitas fisik sebagai stimulator yang kuat dari proses neurogenesis, synaptogenesis, dan brain vasculature. Disisi lain neurogenesis adalah proses dimana sistem sel saraf menghasilkan neuron. Sloane E. 2004 mengungkapkan bahwa 'Neuron sensorik (aferen) menghantarkan impuls listrik dari reseptor pada kulit, organ indera, atau suatu organ internal ke SSP. Neuron motorik menyampaikan impuls dari SSP ke efektor. Interneuron (neuron yang berhubungan) ditemukan seluruhnya dalam SSP. Neuron ini menghubungkan neuron sensorik dan motorik atau menyampaikan informasi ke interneuron lain'.

Dukungan penelitian ini untuk penulis adalah memperkuat asumsi penulis bahwa dengan latihan gerak, terutama latihan koordinasi dan multitasking, seperti juggling, dapat menyebabkan perubahan pada struktur otak, yang dimana latihan Life Kinetik mencangkup latihan koordinasi dan multitasking. Sejalan juga dengan penelitian yang dilakukan oleh Prasanti F. D. (2015) yang berjudul "Pengaruh Brain Gym terhadap konsentrasi belajar pada siswa kelas VIII SMP Surakarta" yang mengungkapkan bahwa

Ada perbedaan yang signifikan antara skor tingkat keterampilan pada kelompok eksperimen antara sebelum mendapatkan perlakukan dan sesudah mendapatkan perlakuan berupa brain gym yaitu dengan nilai z skor pada uji Wilcoxon pretest dan posttest tingkat konsentrasi belajar.

\section{KESIMPULAN DAN SARAN}

Penelitian ini menyimpulkan bahwa terdapat pengaruh yang signifikan dari pelatihan Life Kinetik terhadap peningkatan keterampilan pada atlet bola voli. Hasil penelitian ini mengungkapkan bahwa latihan Life Kinetik dapat meningkatkan keterampilan atlet putri bola voli secara signifikan. Dengan meningkatnya konsentrasi atlet, maka meningkatnya kemampuan pun sangat memungkinkan bahkan mendapatkan kemenangan dalam sebuah pertandingan. Hal ini pada dasarnya mendukung pernyataan yang mengatakan bahwa keterampilan atlet akan menentukan baik-tidaknya atau menang-kalahnya suatu tim. 


\section{DAFTAR PUSTAKA}

Cox, R. H. (1980). Teaching volleyball. Burgess Publishing Company.

Jatikusuma, M. I. (2017). Pengaruh Latihan Life Kinetik Terhadap Konsentrasi dan Hasil Belajar Keterampilan Bolabasket. (Doctoral dissertation, Universitas Pendidikan Indonesia).

Kiswari Rukman. (2014). Hematologi \& Transfusi. Jakarta : Erlangga.

Komarudin. (2018). Life Kinetik dan Performa Psikologis. Bandung. PT Remaja Rosdakarya.

Komarudin. (2018). Life Kinetik pada Cabang Olahraga beregu dan Perorangan. Jurnal Sosioteknologi, 17(1), 22.

Kuswari, Hari, (2014). Pelatihan Life Kinetik. Tersedia di: http://brain jogging@hotmail.com.

Purwanto, D. (2012). Survey kondisi fisik dan keterampilan teknik dasar bola voli pada klub bola voli putri bravo banjarnegara tahun 2012 (Doctoral dissertation, Universitas Negeri Semarang).

Putra, Y. P., Nurseto, F., \& Surisman, S. (2013). Hubungan Tingkat Kepercayaan Diri dan Motivasi dengan Keterampilan Gerak Dasar Sepakbola. JUPE (Jurnal Penjaskesrek), 1(3).

Saputra, M. Y., \& Sartono, H. (2017, March). Optimization of Pencak Silat Athletes Coordination Through Life Kinetik. In IOP Conference Series: Materials Science and Engineering (Vol. 180, No. 1, p. 012216). IOP Publishing.

Sloane E. 2004. Anatomi dan fisiologi untuk Pemula. Jakarta: EGC. hlm. 291. 